\title{
El Sagrario de San Mateo de Lucena (Córdoba) como capital simbólico en los mecanismos de ascenso social*
}

\author{
Clara Sánchez Merino \\ Universidad de Córdoba \\ clsanchezmerino@gmail.com
}

Habida cuenta de los múltiples trabajos que se han dedicado al estudio del Sagrario lucentino ${ }^{1}$, es conveniente aclarar que la mayoría emplean una metodología de trabajo que encuentra su razón de ser en la descripción artística del monumento, sin profundizar en otros fenómenos de carácter social y antropológico que se ven involucrados en la concepción final de la obra. Creemos preciso plantear estas fórmulas artísticas como las claves para comprender cómo funcionaban los mecanismos de ascenso social en la Lucena del siglo XVIII y concebir el Sagrario como la producción de capital simbólico (Bourdieu, 2002 y 2010) [1].

La construcción del Sagrario es un ejemplo de que los nuevos preceptos clásicos de la Real Academia de Bellas Artes de San Fernando, creada por Real Decreto de 12 de abril en 1752 (Rodríguez, 1992), están teniendo un alcance favorable en un radio escaso de distancia, pero estas nuevas soluciones artísticas no se han conseguido implantar en el imaginario cultural del resto de territorios de la corona, en los que las formas aún están cargadas de dinamismo y profusión (Rivas, 1986, Belda, 1992 y Rodríguez, 1992).

En Lucena se prolonga esta tendencia, el Sagrario es una significativa prueba de ello². La aplicación de novedosos diseños decorativos no obedece a razones únicamente estéticas, lejos de ello, hemos de dirigir la mirada hacia otro tipo de implicaciones sociales y políticas [2]. En efecto, una de las causas sería el gusto popular. El pueblo se sentía más identificado con este tipo de ornamentación y, al fin y al cabo, la construcción del Sagrario no sólo suponía la edificación de un espacio sagrado, sino que también se constituía como monumento identificativo de la ciudad. Esto lo tenían

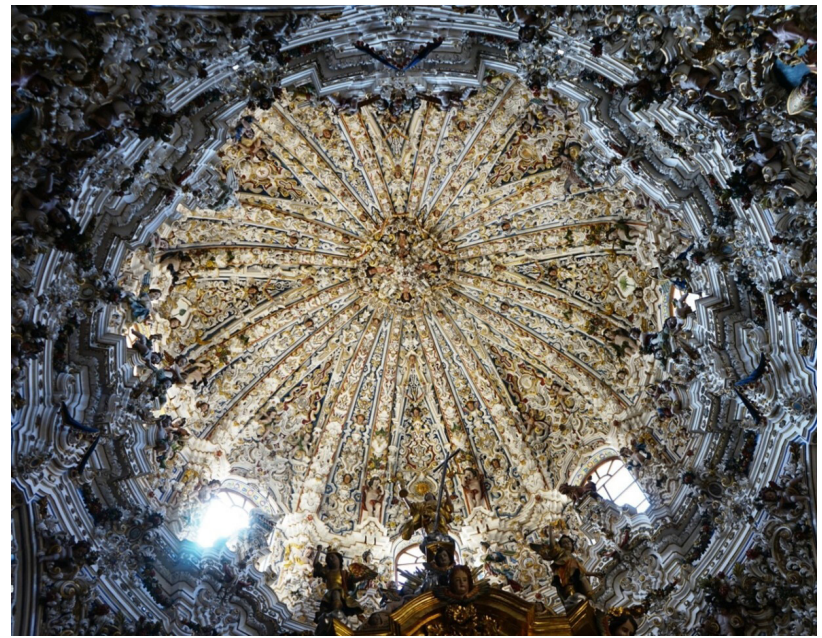

1. Cúpula del Sagrario de San Mateo de Lucena

muy claro los hermanos mayores de la cofradía del Santísimo Sacramento, quienes sentían la necesidad de promocionarse socialmente, para lo que financiaron la edificación de la capilla del Sagrario. Podemos identificar este hecho como un asunto de interés colectivo, que en cierta medida es, pero, además, hemos de tener presente que la cofradía del Santísimo Sacramento era una institución religiosa de la que formaban parte algunos miembros de la élite local. Pese al sentimiento de pertenencia a la comunidad, cada individuo tenía bien definido su horizonte de intereses y, en consecuencia, cada uno asumía un rol en el juego de poder.

A través de la revisión del caso de Antonio José de Valdecañas y Piédrola (1727-1808) mostraremos cómo estos

Cómo citar este artículo: SÁNCHEZ MERINO, Clara, "El Sagrario de San Mateo de Lucena (Córdoba) como capital simbólico en los mecanismos de ascenso social», Boletín de Arte-UMA, n. ${ }^{\circ}$ 42, Departamento de Historia del Arte, Universidad de Málaga, 2021, pp. 289-293, ISSN: 0211-8483, e-ISSN: 2695-415X, DOI: http://dx.doi. org/10.24310/BoLArte.2021.vi42.12229 


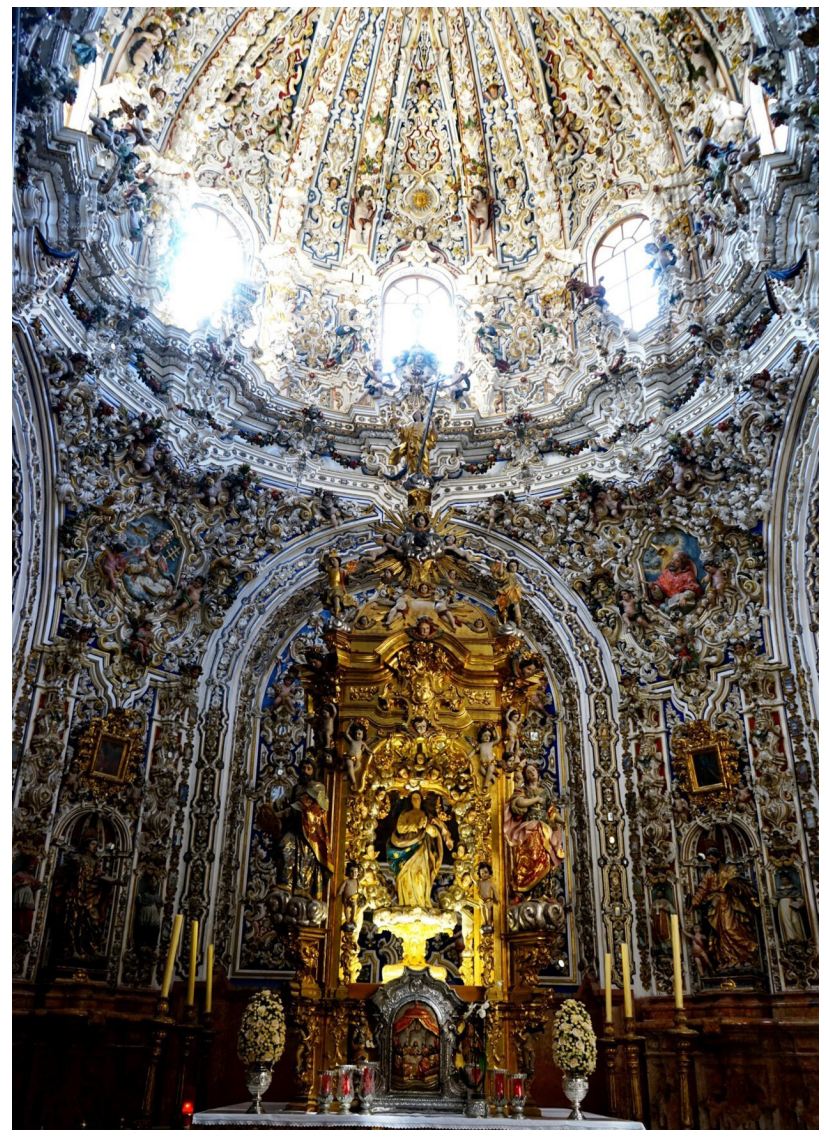

2. Detalle del tabernáculo del Sagrario de San Mateo de Lucena

miembros de la élite lucentina trazaron unas estrategias de proyección que daban sentido a su existencia como parte integrante, a su vez, de una trayectoria social más amplia, como es la dirección de los mecanismos de ascenso social que diseñaba la familia a la que pertenecía (Soria, 2007, Gómez, 2009 y Extremera, 2011). Fernando Recio Chacón de Rojas Valle y Becerra ${ }^{3}$ fue quien ocupó el cargo de hermano mayor de la cofradía y se encargó de celebrar una junta particular junto con el resto de los hermanos para la construcción del nuevo Sagrario ${ }^{4}$. Recio Chacón fue uno de los miembros más ilustres de Lucena, dado que ya su padre, Gabriel Recio Chacón, era conocido por sus viñas en Monturque y Lucena (Barea, 2014: 111). Estos datos no son insignificantes si tenemos en consideración que la cofradía desde su fundación designaba como hermano mayor un hombre de entre los más distinguidos y principales de la patria lucentina que conformaban la élite local ${ }^{5}$.
Antonio José de Valdecañas también fue elegido hermano mayor por junta general anual de la cofradía del Santísimo Sacramento el domingo 8 de junio de $1766^{6}$. Al igual que Recio Chacón, Valdecañas pertenecía a una familia con una importante y rica propiedad ganadera que, aunque no poseía título nobiliario (Palma, 2016), su posición social ascendía por mor de sus propiedades en rentas, casas, edificios agrícolas y tierras ${ }^{7}$. No es de extrañar que la casa ducal de Medinaceli se molestara por la posición local de esta familia. Fue a raíz del impedimento que el duque manifestó en contra de la construcción de un molino de harina que Valdecañas quería llevar a cabo. La razón por la que el duque quiso evitar tal construcción se debía al temor de que el poder de Valdecañas continuara creciendo.

Estos enfrentamientos cobraron mayor fuerza, sumándose también los intereses de la corona. Terminó siendo favorable para la realeza, que consiguió la revocación de la jurisdicción de este territorio a su poder (Estepa, 1987). Por su parte, Valdecañas se comprometió con la causa de la corona, posicionándose como apoderado local en el pleito de reversión (Villalba, 2005), a lo que tendríamos que añadir el servicio directo que prestó durante décadas a la monarquía a cambio de concederle el título nobiliario en 1791 (Palma, 2016 y Windler, 1997) ${ }^{8}$.

El Sagrario se convierte en un símbolo de triunfo de la élite local lucentina frente al poder ejercido por el duque de Medinaceli (Villalba, 2005). Este hecho se pone de manifiesto en la sincronicidad con la que se efectúa la resolución del pleito contra el duque por medio de la real carta ejecutoria

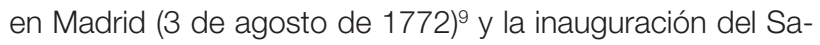
grario (19 de marzo de 1772) ${ }^{10}$. En este tiempo Valdecañas está en el momento más álgido de su promoción social, habiendo desempeñado los cargos de teniente corregidor real y de alcalde mayor, ocupando también el cargo de familiar del Santo Oficio para conseguir, más adelante, ejercer como alguacil mayor del Santo Oficio ${ }^{11}$. En efecto, Valdecañas transitó por diferentes caminos hasta que consiguió formar parte de la nobleza, pero era sabedor de que su contribución a la financiación de la construcción del Sagrario sería una de las vías más efectivas.

Para comprender la significación del Sagrario en tanto representación de la operación de reconocimiento ha sido indispensable la consulta del manuscrito de Andrés Francisco de Valdecañas y Piédrola ${ }^{12}$, hermano de Antonio José de 
3. Fragmento del manuscrito de Andrés Francisco de Valdecañas y Piédrola, Descripción puntual y relación genuina del magestuoso fausto, y cathólico reverente culto, con que la mui ylustre cofradía del Santísimo Sacramento, de la mui leal antigua, y siempre fiel ciudad de Lucena, celebró en el día 2 de mayo del presente año de 1772 (...)

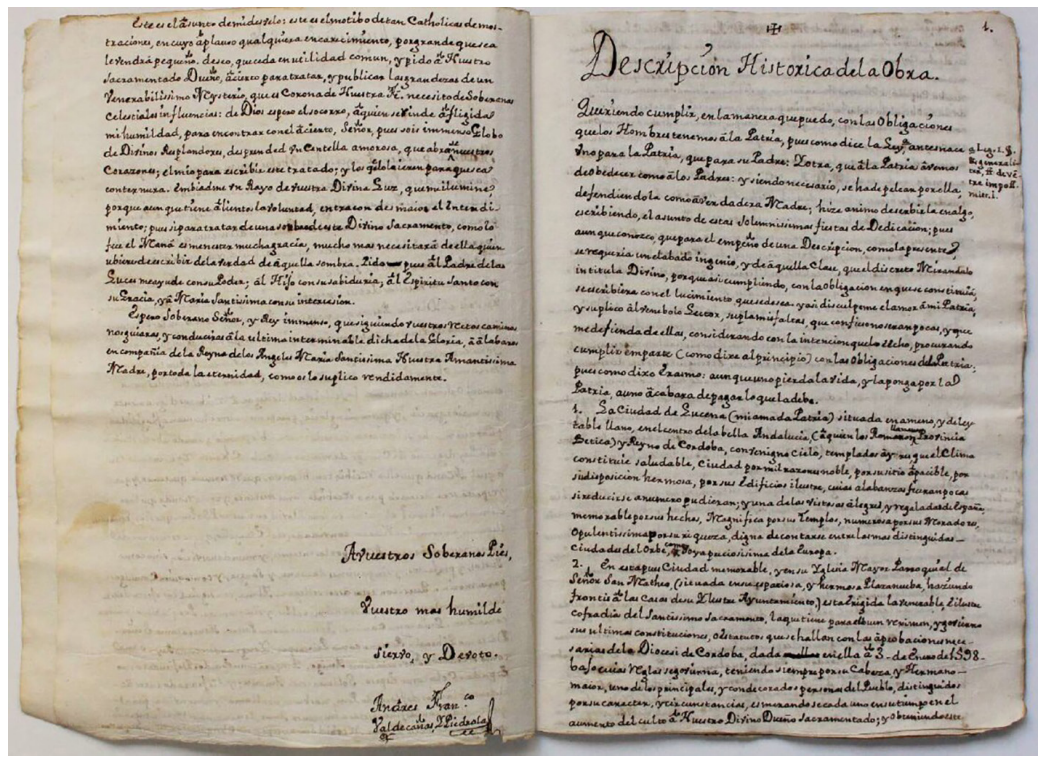

Valdecañas y Piédrola [3]. Del manuscrito se desprende que Andrés Francisco de Valdecañas fue testigo ocular de las obras que tuvieron lugar en el nuevo Sagrario, además de ser hermano de Antonio José de Valdecañas, lo cual contribuye a reforzar en mayor medida las declaraciones que éste realiza en el manuscrito. Informa que las obras del Sagrario comenzaron el martes 16 de agosto del año 1740 y terminaron el 19 de marzo de 1772. Asimismo, indica que la consagración tuvo lugar el día 2 de mayo, una ocasión idónea para Antonio José de Valdecañas, quien financió la undéci- ma fiesta y vio en estas celebraciones una excelente vía para demostrar su aportación al nuevo Sagrario.

En conclusión, partiendo de la consulta de fuentes de diversa naturaleza, hemos pretendido realizar un estudio en el que se conciba el Sagrario de San Mateo como una obra artística compleja que explique las distintas dinámicas sociales. Esto es, el Sagrario como verdadera concreción visual, no sólo de la religiosidad de unos grupos, sino también de sus operaciones de ascenso social, uniendo campos de intereses muy amplios.

\section{Notas}

* Este trabajo se inscribe en el marco del proyecto de investigación La mesocracia en la Andalucía de los siglos XVI y XVII. Poder, familia y patrimonio (PID2019-109168GB-I00), dirigido por los Dres. Enrique Soria Mesa y Luis Salas Almela y financiado por el Ministerio de Ciencia e Innovación.

1 Destaca la aportación de Rivas Carmona (1982) al conocimiento de las obras arquitectónicas nacidas en el seno del siglo XVIII cordobés. Si bien escasean los estudios que sitúen al Sagrario como el elemento desencadenante de mecanismos de movilidad social, no podemos dejar de mencionar algunos trabajos que plantean interesantes cuestiones, abriendo nuevas vías de estudio en comunión con los planteamientos metodológicos que presentamos. Serrano, 2017 y Villalba, 2005.

2 Fue necesario que Carlos III dictase dos reales órdenes en 1777 por las que prohibía iniciar obra alguna sin que antes fuesen sus proyectos supervisados: Rodríguez, 1992: 20. Por ello, es de suponer que el proyecto de construcción del Sagrario fue posible llevarlo a término por la anticipación, dado que las obras comenzaron en 1740 y finalizaron en 1772, cuando las dos reales órdenes aún no habían sido dictadas. La Comisión de Arquitectura (creada en 1786) habría modificado sustancialmente el proyecto para adecuarlo a las nuevas normas del buen gusto.

3 Fernando Recio Chacón de Rojas Valle y Becerra fue alcaide del castillo y fortaleza de Chillón. Testó en 1724, casado en Morente en 1705 con Elvira María de Guzmán (el Bueno) y Cárdenas, de Córdoba. Será su nieto, Martín José Chacón y Hogazón, nacido en Lucena, quien obtendrá el título de Marqués de Campo de Aras en 1806. El caso de los Recio Chacón representa un patrón de conductas ordenadas por y para conseguir que la familia perteneciera a la alta nobleza y se trata, por tanto, de otro ejemplo de ascenso que se encuentra relacionado con el patrocinio del Sagrario lucentino. Barea, 2014: 111.

4 Valdecañas, 1772: 1r.

5 «(...) la venerable ilustre cofradía del Santísimo Sacramento, la que tiene para el buen régimen y gobierno sus últimas constituciones, o estatutos, que se hallan con las aprobaciones necesarias de la Diócesis de Córdoba, dada en ella a 3 de enero de 1598 bajo cuyas reglas se gobierna, teniendo siempre por su 
cabeza y Hermano mayor, uno de los principales y condecorados personas del Pueblo, distinguidos por su carácter, y circunstancias, esmerándose cada uno en su tiempo en el aumento del culto a Nuestro Divino Dueño Sacramento y obteniendo este honro encargo por los años de 1746 Don Fernando Recio Chacón de Rexas». Valdecañas, 1772: $1 \mathrm{r}$.

6 Valdecañas, 1772: $1 \mathrm{r}$.

7 Otros bienes de la familia hacían aumentar este número, alcanzando un producto de 15.663 reales (entre ellos 101 hectáreas de tierra), propiedades en las que Valdecañas también participaba. También poseían tierras en Priego. Windler, 1997: 159.

8 La familia Valdecañas recibió recompensas muy significativas a cambio de cumplir fielmente los mandatos regios. Una de las recompensas que obtuvo Valdecañas fue la de ser nombrado visitador general del ramo de Caballería, además del propio título condal de Valdecañas, con el vizcondado previo de Anjarón, dispensado por Carlos IV en 1791. Se puede consultar el título de concesión en el Archivo Histórico Municipal de Lucena, Actas capitulares, 1791-7-12. Un fragmento del título de concesión ha sido transcrito por Palma (2016), en el cual se referencia a los valores y otros servicios meritorios que Valdecañas prestó al rey y le hicieron merecedor de tales prebendas.

9 El 29 de marzo de 1757 comenzó el juicio ordinario, el 18 de enero de 1767 se falló en contra del duque, después la sentencia de revista de 8 de enero de 1770 confirmó la anterior y una real carta ejecutoria en Madrid de 3 de agosto de 1772 ordenó que se cumpliese lo dispuesto anteriormente. Bernardo, 1981 : 28-29; 60-6 1 y 73-76 y Villalba, 2005: 66.

10 «(...) en el día jueves 19 de marzo del presente año de 1772, se vio este suntuosísimo Sagrario perfectamente concluido tocándole en suerte esta grande fortuna a don Antonio José Valdecañas y Piédrola, desempeñando el cargo de hermano mayor». Valdecañas, 1772: 2v.

11 Valdecañas, 1772: 2v.

12 El manuscrito (Valdecañas, 1772) se halla recogido en Apuntes para una Historia de Lucena (Rodríguez, 1960). También ha sido mencionado por los autores Rivas (1982) y Taylor (1978) partiendo de otras transcripciones previas, pero de forma parcial y fragmentaria. En el presente artículo aportamos datos que han sido extraídos de la consulta de una copia digitalizada del manuscrito original (de propiedad privada, cedido por Francisco de Asís Requerey Ramírez) que ha sido puesto a nuestra disposición gracias a la amabilidad de Francisco Escudero Ruiz y Rosa María López Moreno, del Archivo Parroquial de San Mateo de Lucena.

\section{Bibliografía}

BAREA LÓPEZ, Óscar (2014), Heráldica y genealogía en el sureste de Córdoba (S.s. XIII-XIX). Linajes de Baena, Cabra, Carcabuey, Doña Mencía, Iznájar, Luque, Monturque, Priego, Rute, Valenzuela y Zuheros, Bubok Publishing, Madrid.

BELDA NAVARRO, Cristóbal y DE LA PEÑA VELASCO, Concepción (1992), «La visión de un mundo en crisis: Los gremios frente a la Academia», en El arte español en épocas de transición: actas del IX Congreso Español de Historia del Arte, Comité Español de Historia del Arte Universidad de León, León, pp. 17-26.

BERNARDO ARES, José Manuel de (1991), «La decadencia de los señoríos en el siglo XVIII. El caso de Lucena», en CALVO POYATO, José (coord.), Lucena: apuntes para su historia. I Jornadas de Historia de Lucena, Lucena, pp. 61-83.

BOURDIEU, Pierre (2002), Campo de poder, campo intelectual. Itinerario de un concepto, Montressor, Madrid.

BOURDIEU, Pierre (2010), El sentido social del gusto. Elementos para una sociología de la cultura, Siglo Veintiuno, Madrid.

CHARTIER, Roger (1999), El mundo como representación. Estudios sobre historia cultural, Gedisa, Barcelona.

ESTEPA GIMÉNEZ, Jesús (1987), El marquesado de Priego en la disolución del régimen señorial andaluz, Diputación Provincial de Córdoba, Córdoba.

EXTREMERA EXTREMERA, Miguel A. (2011), «El ascenso frustrado de una mesocracia emergente a una burguesía ausente (Córdoba 15001800)», Historia y Genealogía, n. ${ }^{1}$, pp. 23-39.

GÓMEZ CARRASCO, Cosme Jesús (2009), «Herencia y transmisión del patrimonio a finales del Antiguo Régimen. Diferentes estrategias en la comunidad mercantil y en la élite local (Albacete, 1750-1830)", Investigaciones Históricas, n. ․ 29, pp. 97-128.

LÓPEZ DE CÁRDENAS, Fernando José (1777), Memorias de la ciudad de Lucena y su territorio, con varias noticias de erudición pertenecientes á la Betica, Imprenta de Benito Daza, Écija.

PALMA ROBLES, Luis Fernando (2016), «El II Conde de Valdecañas, militar lucentino, en el primer cuarto del siglo XIX y su relación con Montilla», Crónica de Córdoba y sus pueblos, XXIII, Diputación de Córdoba, Córdoba, pp. 87-108.

RIVAS CARMONA, Jesús (1982), Arquitectura barroca cordobesa, Publicaciones del Monte de La Piedad y Caja de Ahorros de Córdoba, Córdoba.

RIVAS CARMONA, Jesús (1986), «Notas para el Neoclásico cordobés», Imafronte, n. 2, pp. 25-55.

RODRÍGUEZ G. DE CEBALLOS, Alfonso (1992), El siglo XVIII, entre tradición y academia, Sílex, Madrid. 
SERRANO MÁRQUEZ, Nereida (2017), «Piedad, prestigio y poder. Patronatos y proyección de arquitectura religiosa en la Lucena del siglo XVIII», en RODRíGUEZ MIRANDA, María del Amor y PEINADO GUZMÁN, José Antonio, El barroco: universo de experiencias, Asociación Hurtado Izquierdo, Córdoba, pp. 147-168.

SORIA MESA, Enrique (2007), La nobleza en la España Moderna. Cambio y continuidad, Marcial Pons Historia, Madrid.

VALDECAÑAS Y PIÉDROLA, Andrés Francisco (1772), Descripción puntual y relación genuina del magestuoso fausto, y cathólico reverente culto (...). Copia digitalizada cedida por el Archivo Parroquial de San Mateo de Lucena.

VILLALBA MUÑOZ, José Antonio (2005), «Señoriales y antiseñoriales, primero; aracelitanos y sanjorgistas, después. Tensiones contra la nobleza durante la segunda mitad del siglo XVIII en Lucena», Revista de Estudios de Ciencias Sociales y Humanidades, n. ${ }^{\circ} 14, \mathrm{pp}$. 61-75.

WINDLER, Christian (1997), Élites locales, señores, reformistas. Redes clientelares y Monarquía hacia finales del Antiguo Régimen, Universidad de Sevilla, Sevilla. 